\title{
Improving performance through human-centred reconfiguration of existing designs
}

\section{Ken Catchpole}

Correspondence to

Dr Ken Catchpole, Department of Surgery, Cedars Sinai Medical Centre, Suite 302, 8797 Beverly Blvd, Los Angeles, CA 90048, USA; ken.catchpole@cshs.org

Published Online First 3 December 2012

\section{SLinked}

http://dx.doi.org/10.1136/ bmjqs-2012-001134
To cite: Catchpole K. BMJ Qual Saf 2013;22:5-7.
Understanding and improving the relationship between people and their working environment can reduce the chance of errors, improve human performance and thus enhance the performance of the whole system. ${ }^{1}$ One way of achieving this is to train humans to better understand the environment that surrounds them. Another is to configure a better environment in the first place. As technology advances, so the multitude of ways to achieve this latter aim increases, and the more important it becomes to consider not just what the technology can do but what it should do to assist humans. This human-centred approach to systems-the science and practice of what is now known as human factors engineering (or ergonomics)-has not always been prevalent ${ }^{2}{ }^{3}$ but has become a key component of how we develop better ways of doing things, especially in the military, transport and high-risk industrial domains. In healthcare, this realisation has been slower but is now also becoming widely recognised.

The application of human factors in healthcare has largely focused on problem identification and training based on models from aviation. ${ }^{4}$ Though this has produced some notable successes, ${ }^{5}$ substantial and sustained behavioural change remains a challenge. ${ }^{6}$ A key limitation of this approach in healthcare is the superimposition of training on systems that are already deficient in design and thus continue to be predisposing to error. ${ }^{7}$ In the application of training, checklist and other behavioural adaption principles from other high-risk industries, the extant level of humancentred engineering in these industries has been somewhat forgotten. All too often we place the emphasis on changing humans because they are flexible and adaptive, and hold the components (technological or otherwise) together. ${ }^{8}$ Instead, technology that does not function in the workplace as anticipated should be seen as a problem for the design and configuration of the equipment, not the human beings. ${ }^{9} 10$

A growing number of studies of healthcare equipment find that technology may not support the users in the best way, ${ }^{11-13}$ creating the opportunity for error that would be best avoided through better design rather than training. In this journal several recent papers ${ }^{14} 15$ and commentaries $^{15}{ }^{16}$ have expounded this argument, while changes in regulatory advice and standards reflect the recognition that human factors engineering should be incorporated earlier and more comprehensively into device development. ${ }^{17}{ }^{18}$ Eventually, equipment designs better suited to human abilities will be more prevalent. This in turn will result in fewer errors, improved safety and quality, and overall better system performance, without having to rely solely on expensive and brittle behavioural solutions. ${ }^{19} 20$ Indeed, focusing on technological reconfiguration rather than training may bring about human performance changes that direct behavioural intervention may be ineffective at addressing.

Human factors integration is the term generally used to describe the top-down assimilation of human-centred considerations in systems engineering. For example, the US Army's MANPRINT programme and the UK Human Factors Integration Defence Technology Centre focus on ensuring the needs of the solider are met throughout the lifecycle of a system, as failures to do so in the past have proven costly in money and lives. ${ }^{21}$ These programmes support the development of equipment and training together through a human-centred approach, working at different levels within the services to 
improve human-system integration. Cooke and Durso $^{22}$ also offer an interesting perspective on systems design and human integration, exploring how expertise in cognition has been applied to a range of engineering problems. A great many books are also available that derive their evidence largely from space, transport, defence and energy industries, which makes these arguments difficult to ignore. ${ }^{23} 24$

However, a word of caution is needed. Healthcare may be faced with three particular problems that are less prevalent in these other industries. First, few healthcare systems are acquired as a 'whole'. Rather, each hospital acquires different technologies at different times, resulting in a complex amalgam of equipment of varied design, origin, purpose and age, making technological, let alone human, integration challenging. Second, as systems are only replaced periodically, better human-centred technology may take a long time to reach clinicians, meaning that deficient systems remain in use that predispose to error and harm. We need to consider how these problems might be addressed more immediately. Finally, despite substantial progress towards better designed systems, and considerable clinical engagement in human factors and quality solutions, there is still a gap between research and practice in the development and procurement of human-centred technology. In short, how can we take the best principles and apply them now, to address the needs of clinicians who feel that they may be 'stuck' with a system that needs fixing?

In this issue, Kobayashi and colleagues ${ }^{25}$ describe an intervention to do just that. They demonstrate improvements in performance with an existing technology by reconfiguration based on human factors engineering principles. This is an original approach to a problem that is technological, yet is initiated by and thoroughly developed at the clinical interface. The authors' approach consists of more than just training, a checklist or process standardisation and thus does not rely on direct behavioural change. Instead, the approach focuses on reconfiguring system components within the influence of the clinicians to address a recognised local deficiency and clinical need. With this approach, successfully reconfiguring the system produces behavioural changes-in this case, more appropriate responses to patient deterioration-in contrast to the traditional approach in healthcare, namely exhorting staff to pay more attention or be more careful.

The approach covers several dimensions of human factors (physical, cognitive, organisational), illustrating the systems view that improvements do not happen in isolation; rather, that a thorough understanding of the mismatch between technology and human requirements can lead to a range of small fixes that together add up to a wholesale improvement. This, therefore, is human-systems integration at the 'sharp end' of care that provides a practical approach to technological improvement for the benefit of staff and patients.

Sufficient application of the right expertise brings the opportunity to improve upon the use of existing technology through better equipment and workplace configuration. This innovative approach is not frequently documented in other industries, though it almost certainly is extant there, and is a particularly valuable approach for healthcare. However, challenges remain. Though it may be easy to regard this type of work as 'common sense' in fact it can be technically challenging and uncertain. Knowing where and when to use this type of solution is another important consideration. Kobayashi's team was large and multidisciplinary. That range of expertise is often not available. In particular, if human factors expertise is a required component of this approach it needs to be cost effective and scalable. Access to this type of expertise in healthcare lags behind that of other industries, which suggests that training in human factors for healthcare should not just be limited to aviation style teamwork, but to a more human-centred systems approach. In conjunction with clinical expertise, and iterative improvement cycles, this could be a powerful combination. Furthermore, if each mismatch between human and technology needs to be carefully considered in this way, we will need an approach that allows wider utilisation, and a more universal recognition that equipment design or reconfiguration will be essential in an industry that is still predominantly focused on individual skills for avoiding errors. Finally, we need to spread this user-centred reconfiguration of technology to other clinicians and hospitals, and also to the manufacturers to encourage better original designs.

The experience of human-centred design in a range of other industries is that it saves lives and money. How similar integration of human and system might be achieved in healthcare is a question worth focusing on, because ultimately, it is something that will almost certainly benefit our clinicians and our patients.

Funding Dr Catchpole is gratefully supported by grant funding W81XWH-10-1-1039 from the United States Department of Defense, Telemedicine and Advanced Technology Research Center (TATRC) of the US Army Medical Research and Material Command.

Competing interests None.

Provenance and peer review Not commissioned; internally peer reviewed.

\section{REFERENCES}

1 Salvendy G. Handbook of Human Factors. Hoboken, New Jersey: John Wiley \& Sons, 2006.

2 Parasuraman R, Riley V. Humans and automation: use, misuse, disuse, abuse. Hum Factors 1997;39:230-53.

3 Bainbridge L. Ironies of automation. Automatica 1983;19:775-9. 
4 Leonard M, Graham S, Bonacum D. The human factor: the critical importance of effective teamwork and communication in providing safe care. Qual Saf Health Care 2004;13(Suppl. 1):i85-90.

5 Young-Xu Y, Neily J, Mills PD, et al. Association between implementation of a medical team training program and surgical morbidity. Arch Surg 2011;146:1368-73.

6 McCulloch P, Rathbone J, Catchpole K. Interventions to improve teamwork and communications among healthcare staff. Br J Surg 2011;98:469-79.

7 Catchpole KR, Dale TJ, Hirst DG, et al. A multicenter trial of aviation-style training for surgical teams. J Patient Saf 2010;6:180-6.

8 Dekker SW. The Field Guide to Human Error Investigations. Aldershot: Ashgate, 2002.

9 Woods D, Sarter N, Billings C. Automation surprises. In: The Handbook of Human Factors and Ergonomics. 2nd edn. New York: John Wiley and Sons, 1997.

10 Weinger MB, Gardner-Bonneau D, Wiklund ME, et al. Handbook of Human Factors in Medical Device Design. Boca Raton, Florida: CRC Press, 2011.

11 Fairbanks RJ, Caplan S. Poor interface design and lack of usability testing facilitate medical error. Jt Comm J Qual Saf 2004;30:579-84.

12 Wiegmann D, Suther T, Neal J, et al. A human factors analysis of cardiopulmonary bypass machines. J Extra Corpor Technol 2009;41:57-63.

13 Fairbanks RJ, Caplan SH, Bishop PA, et al. Usability study of two common defibrillators reveals hazards. Ann Emerg Med 2007;50:424-32.

14 de Korne DF, van Wijngaarden JDH, van Rooij J, et al. Safety by design: effects of operating room floor marking on the position of surgical devices to promote clean air flow compliance and minimise infection risks. BMJ Qual Saf 2011;21:746-52.

15 Gurses AP, Kim G, Martinez EA, et al. Identifying and categorising patient safety hazards in cardiovascular operating rooms using an interdisciplinary approach: a multisite study. BMJ Qual Saf 2012;21:810-8.

16 Norris BJ. Systems human factors: how far have we come? BMJ Qual Saf 2011;21:713-4.

17 International Organization for Standardization. ISO 9241210:2010. Ergonomics of Human-System Interaction-Part 210: Human-centred Design for Interactive Systems. Geneva: ISO, 2010.

18 US Food and Drug Administration. Draft Guidance for Industry and Food and Drug Administration Staff: Applying Human Factors and Usability Engineering to Optimize Medical Device Design. 2011. http://www.fda.gov/downloads/ MedicalDevices/DeviceRegulationandGuidance/ GuidanceDocuments/UCM259760.pdf (accessed 19 November 2012).

19 Department of Health. Design for Patient Safety. London: Department of Health and Design Council, 2004.

20 Weinger MB, Pantiskas $\mathrm{C}$, Wiklund ME, et al. Incorporating human factors into the design of medical devices. JAMA 1998;280:1484.

21 Human Factors Integration Defence Technology Centre. Cost Arguments and Evidence for Human Factors Integration. 2006. http:/www.hfidtc.com/pdf-downloads/cost-just-hfi.pdf (accessed 19 November 2012).

22 Cooke NJ, Durso FT. Stories of Modern Technology Failures and Cognitive Engineering Successes. Boca Raton, Florida: CRC Press, 2008.

23 Strauch B. Investigating Human Error: Incidents, Accidents, and Complex Systems. Aldershot: Ashgate, 2004.

24 Proctor RW, Van Zandt T. Human Factors in Simple and Complex Systems. Boca Raton, Florida: CRC Press, 2008.

25 Kobayashi L, Parchuri R, Gardiner FG, et al. Use of in situ simulation and human factors engineering to assess and improve emergency department clinical systems for timely telemetry-based detection of life-threatening arrhythmias. BMJ Qual Saf 2012. 